\title{
Pengaruh Konsentrasi Pupuk Organik Cair terhadap Pertumbuhan dan Hasil Beberapa Varietas Tanaman Tomat (Lycopersicum esculentum Mill.)
}

\section{The Effect of Organic Fertilizer Concentration on Growth and Yield of Several Tomato Plant Varieties (Lycopersicum esculentum Mill.)}

\author{
Fitri Yanti ${ }^{1}$, Jumini ${ }^{1}$, Ainun Marliah ${ }^{1}$ \\ ${ }^{1}$ Program Studi Agroteknologi PSDKU Gayo Lues, Fakultas Pertanian, Univeristas Syiah Kuala \\ fitriyanti0221@gmail.com
}

\begin{abstract}
Abstrak. Penelitian ini bertujuan untuk mengetahui pengaruh konsentrasi pupuk organik cair dan varietas yang tepat serta interaksi antara kedua faktor tersebut terhadap pertumbuhan dan hasil tanaman tomat. Penelitian ini dilaksanakan di Desa Peparik, Kecamatan Blangjerango, Kabupaten Gayo Lues dan Laboratorium Dasar Kampus USK PSDKU Gayo Lues, berlangsung dari bulan Januari sampai Maret 2021. Rancangan Penelitian yang digunakan adalah Rancangan Acak Kelompok pola faktorial 4x3 dengan 3 ulangan sehingga terdapat 12 kombinasi perlakuan dan 36 unit percobaan. Faktor yang diteliti yaitu konsentrasi pupuk organik cair super ACI yang terdiri dari 4 taraf yaitu $0,1.5,3,4.5 \mathrm{ml} / \mathrm{L}$ air dan varietas yang terdiri dari 3 taraf yaitu lokal Gayo, Cheery dan Karina. Hasil penelitian menunjukkan bahwa Konsentrasi pupuk organik cair super ACI berpengaruh tidak nyata terhadap tinggi tanaman, diameter batang umur 15, 30 dan 45 HST, umur berbunga, jumlah buah per tanaman, jumlah buah per tandan, bobot buah per tanaman, bobot buah per buah dan potensi hasil. Pertumbuhan dan hasil tanaman tomat cendrung lebih tinggi dijumpai pada konsentrasi pupuk organik cair Super ACI 1,5 ml/ L air. Varietas tomat berpengaruh sangat nyata terhadap tinggi tanaman umur 15 dan 30 HST, umur berbunga, jumlah buah per tanaman, bobot buah per tanaman, bobot buah perbuah, dan potensi hasil namun berpengaruh tidak nyata nyata terhadap tinggi tanaman umur 45 HST, diameter batang umur 15, 30, 45 HST dan jumlah buah per tandan. Pertumbuhan dan hasil tanaman tomat terbaik dijumpai pada perlakuan varietas Lokal. Terdapat interaksi yang tidak nyata antara konsentrasi pupuk organik cair Super ACI dan varietas terhadap pertumbuhan dan hasil tanaman tomat.
\end{abstract}

Kata kunci : Konsentrasi pupuk organik cair, lokal Gayo, Cheery dan Karina.

Abstract.This research was conducted in Peparik Village, Blangjerango Subdistrict, Gayo Lues Regency and THE BASIC Laboratory of USK PSDKU Gayo Lues Campus, lasting from January to March 2021. The research design used is a randomized group of $4 \times 3$ factorial patterns with 3 repeats so that there are 12 combinations of treatments and 36 experimental units. The factors studied are the concentration of ACI super liquid organic fertilizer consisting of 4 levels, namely $0,1.5,3,4.5 \mathrm{ml} / \mathrm{L}$ of water and varieties consisting of 3 levels, namely local Gayo, Cheery and Karina. The results showed that the concentration of super liquid organic fertilizer aCI has no real effect on the height of the plant, the diameter of the stems aged 15, 30 and 45 HST, the age of flowering, the number of fruits per day The growth and yield of higher tomato plants is found in the concentration of Super ACI liquid organic fertilizer of $1.5 \mathrm{ml} / \mathrm{L}$ of water. Tomato varieties have a very real effect on the height of plants aged 15 and 30 HST, flowering age, number of fruits per plant, weight of fruit per plant, weight of fruit, and potential yields but the effect is not noticeable on the height of the plant age of 45.HST, the diameter of the stem is 15,30 , 45 HST and the number of fruits per bunch. The best growth and yield of tomato plants is found in the treatment of local varieties. There is an unreal interaction between the concentration of Super ACI liquid organic fertilizers and varieties to the growth and yield of tomato plants.

Keywords: Concentration of liquid organic fertilizers, local Gayo, Cheery and Karina

\section{PENDAHULUAN}

Tanaman tomat (Lycopersicum esculentum Mill.) merupakan salah satu tanaman semusim dengan sifat pertumbuhannya perdu atau semak yang tumbuh di daerah tropis.Tomat tergolong sayuran buah multiguna dan multifungsi yang dapat dibudidayakan di lahan dataran rendah maupun di dataran tinggi (Alamsyah dan Fitriyah, 2018). Salah satu upaya peningkatan produksi tanaman tomat adalah pemupukan, agar didapatkan pertumbuhan dan hasil tanaman tomat yang baik. Tanaman tomat membutuhkan unsur hara makro maupun mikro, dengan komposisi yang berimbang yang bisa didapatkan dari aplikasi pupuk (Koesriharti et al., 2017). Super ACI merupakan pupuk organik cair lengkapyang mengandung $\mathrm{N}(9,78 \%), \mathrm{P}_{2} \mathrm{O}_{5}$ 
(2,12\%), $\mathrm{K}_{2} \mathrm{O}(6,60 \%), \mathrm{SO}_{4}(2,31 \%), \mathrm{Al}(0,07 \%), \mathrm{Fe}(0,20 \%), \mathrm{Cu}(6,3 \%), \mathrm{Mg}(0,07 \%), \mathrm{pH}$ (7,63\%), Ca (1,10\%). Zn (37,47 ppm), Co (0,17 ppm), Mn (55,62 ppm (Sutanto, 2002). Menurut Suryawati et al. (2013) pemberian pupuk organik cair super ACI pada tanaman terung dapat meningkatkan jumlah buah dan berat buah per tanaman.Pemberian pupuk organik cair super ACI $3 \mathrm{ml} / \mathrm{L}$ air merupakan perlakuan terbaik.Selain pemupukanuntuk meningkatkan produksi tomat dapat juga dilakukan dengan penggunaan varietas yang sesuai. Varietas tomat yang telah dilepas oleh kementerian Pertanian sampai tahun 2006 sebanyak 54 varietas, dan varietas yang sudah dilepas tersebut merupakan varietas anjuran. Beberapa varietas tomat yang telah dilepas diantaranya adalah Karina, Intan, Ratna, Berlian, Mutiara, Kaliurang, Zamrud, Opal, Arthaloka, dan Permata (Wijayanti et al., 2013).

Tomat memiliki beberapa varietas dan masing-masing varietas memiliki bentuk dan ukuran yang berbeda. Varietas Lokal adalah varietas yang dapat memberikan banyak keuntungan, yaitu dapat tumbuh pada ketinggian tempat 1.000-1.500 meter diatas permukaan laut (mdpl) dan toleran terhadap penyakit layu, bentuk buah membulat memiliki umur panen 60-70 hari setelah tanam. (Wijayanti dan Widodo, 2005). Tanaman tomat varietas Karina merupakan jenis benih unggul dengan tipe pertumbuhannya determinane, banyak varietas unggul tomat yang sudah dihasilkan oleh pemulia atau produsen,varietas-varietas tersebut memiliki berbagai sifat yang berbeda satu sama lain seperti produksi, rasa, bentuk, umur panen, ketahanan simpan, dan toleran terhadap penyakit tertentu. Karakteristik buah tomat varietas karina memiliki bentuk buah bulat, seragam, dan agak lembek. Memiliki umur panen 60-70 hari setelah tanam, memiliki rasa manis dan bentuk biji oval (Salli dan Leher, 2016). Varietas Cherry merupakantomat Hibrida, tanaman ini bermanfaat bagi kesehatan, memiliki warna buah merah tua, dan varietas ini tahan terhadap penyakit layu bakteri. Buah tomat varietas Cherry berbentuk lonjong, berat perbuah 13,5-15,0 g, jumlah buah pertanaman 125-133 buah, beradaptasi dengan baik di dataran tinggi dengan altitude 900-1.200 mdpl (Mariati, 2019).

\section{Tempat dan Waktu}

\section{METODE PENELITIAN}

Penelitian ini dilakukan di Desa Peparik, Kecamatan Blangjerango, Kabupaten Gayo Lues dan Laboratorium Dasar Kampus Unsyiah PSDKU Gayo Lues, yang dilaksanakan dari Januari2021 hingga Maret 2021.

\section{Alat dan Bahan}

Alat dan bahan yang digunakan cangkul, parang, garpu, meteran, tali rafia, gembor, selang air, timbangan analitik, pamflet, pisau, jangka sorong, kamera dan alat tulis, benih tomat varietas Lokal Gayo, Karina (unggul) dan Cherry (hibrida), pupuk super ACI $729 \mathrm{~mL}$, pupuk kandang $108 \mathrm{~kg}$, pupuk NPK 3,24 kg, ajir bambu polybag, Insektisida desis 2,5 EC 0,5 ml/L air dan fungisida $1 \mathrm{~g} / \mathrm{L}$ air.

\section{Rancangan Percobaan}

Rancangan yang digunakan pada penelitian adalah Rancangan Acak Kelompok (RAK) pola faktorial 4x3 dengan 3 ulangan sehingga 36 satuan percobaan. Ada dua faktor yang diteliti. Faktor yang diteliti yaitu konsentrasi pupuk organik cair Super ACI (P) yang terdiri atas 4 taraf yaitu $\mathrm{P}_{0}=0 \mathrm{ml} / \mathrm{L}$ air, $\mathrm{P}_{1}=1,5 \mathrm{ml} / \mathrm{L}$ air, $\mathrm{P}_{2}=3 \mathrm{ml} / \mathrm{L}$ air, $\mathrm{P}_{3}=4,5 \mathrm{ml} / \mathrm{L}$ air. Faktor kedua adalah varietas $(\mathrm{V})$ yang terdiri atas 3 taraf $\mathrm{V}_{1}$ : Lokal, $\mathrm{V}_{2}$ : Cherry (Hibrida),

$\mathrm{V}_{3}$ :Karina (Unggul).

\section{Pelaksanaan Penelitian \\ Penyemaian Benih}


Persemaian menggunakan polibag ukuran $5 \mathrm{~cm}$ x $10 \mathrm{~cm}$ media tanam berupa tanah dan pupuk kandang dengan perbandingan 1:1. Setiap polibag diisi 1 benih dan ditanam dengan kedalaman $1 \mathrm{~cm}$.

\section{Pengolahan Lahan dan Pembuatan Bedengan}

Lahan dibersihkan terlebih dahulu dari gulma. Selanjutnya diolah menggunakan cangkul kemudian dibuat bedengan.

\section{Penanaman}

Penanaman dilakukan secara serentak yaitu pada sore hari. Penanaman dilakukan dengan cara membuat lubang tanam dan bibit tomat dimasukkan ke lobang tanam setiap lubang ditanam 1 bibit.

\section{Pemupukan}

Pemberian pupuk organik cair Super ACI dilakukan pada umur 10, 20 dan 30 hari setelah tanam. Konsentrasi pupuk yang digunakan adalah $0,1,5,3$ dan 4,5 ml/L air. Pemberian pupuk yang telah dilarutkan dengan air diberikan dengan cara disiram ke sekitar perakaran tanaman sebanyak $200 \mathrm{ml}$ pertanaman.

\section{Pemeliharaan}

\section{Penyulaman}

Penyulaman dilakukan apabila terdapat tanaman yang tidak tumbuh atau mati dengan menggunakan bibit yang sudah disediakan sesuai dengan varietas.

\section{Penyiraman}

Penyiraman dilakukan dengan menggunakan gembor, yaitu pada pagi dan sore hari atau disesuaikan dengan keadaan bibit tomat dilapangan.

\section{Pemasangan Ajir}

Pemasangan ajir dilakukan dengan menggunakan bilah bambu. Pemasangan ajir dilakukan secara hati-hati agar tidak merusak tanaman.

\section{Pemangkasan}

Pemangkasan dilakukan 2minggu sekali, pemangkasan dilakukan secara hati- hati agar tidak merusak tanaman.

\section{Penyiangan Gulma dan Pembumbunan}

Penyiangan dilakukan dengan cara manual setiap ada pertumbuhan gulma disekitar tanaman, penyiangan dilakukan secara hati-hati agar tidak merusak tanaman selain dilakukan pembersihan gulma penggemburan juga dilakukan pada saat penyiangan.

\section{Pengendalian Hama dan Penyakit}

Pengendalian hama dan penyakit dilakukan secara rutin setiap 7 hari sekali dengan penyemperotan fungisida Karbofurandengan konsentrasi $1 \mathrm{~g} / \mathrm{L}$ air. Penyemperotan dilakukan pada sore hari. hari.

\section{Panen}

Pemanenean dilakukan 5 hari sekali, Pemanenan dilakukan apabila kulit buah berubah dari hijau menjadi kekuning-kuningan. 


\section{Pengematan}

Tinggi Tanaman $(\mathrm{cm})$, diameter batang $(\mathrm{mm})$, umur berbunga (hari), Jumlah buah per tanaman (buah), jumlah buah per tandan (buah), bobot buah per tanaman (g), bobot buah per buah (g), Potensi hasil (ton/ha).

\section{HASIL DAN PEMBAHASAN \\ Pengaruh Konsentrasi Pupuk Organik Cair Super ACI terhadap Pertumbuhan dan Hasil Tanaman tomat}

Hasil analisis ragam menunjukkan bahwa konsentrasi pupuk organik cair super ACI berpengaruh tidak nyataterhadap tinggi tanaman, diameter batang umur 15, 30, dan 45 HST, umur berbunga, jumlah buah pertanaman, jumlah buah pertandan, bobot buah pertanaman,bobot buah per buah dan potensi hasil.

Tabel 1. Rata-rata Pertumbuhan dan Hasil Tanaman Tomat Akibat Perlakuan Konsentrasi Pupuk Organik Cair Super ACI.

\begin{tabular}{|c|c|c|c|c|c|}
\hline \multirow{2}{*}{\multicolumn{2}{|c|}{ Peubah }} & \multicolumn{4}{|c|}{ Konsentrasi pupuk organik cairSuper ACI } \\
\hline & & $\mathrm{P}_{0}(0)$ & $\mathrm{P}_{1}(1,5)$ & $\mathrm{P}_{2}(3)$ & $\mathrm{P}_{3}(4,5)$ \\
\hline \multirow{3}{*}{ Tinggi tanaman $(\mathrm{cm})$} & $15 \mathrm{HST}$ & 22,49 & 24,43 & 23,89 & 23,81 \\
\hline & $30 \mathrm{HST}$ & 61,96 & 65,39 & 64,67 & 65,19 \\
\hline & $45 \mathrm{HST}$ & 82,33 & 84,15 & 80,96 & 83,89 \\
\hline \multirow{3}{*}{$\begin{array}{l}\text { Diameter batang } \\
(\mathrm{mm})\end{array}$} & $15 \mathrm{HST}$ & 3,99 & 4,49 & 4,48 & 4,08 \\
\hline & $30 \mathrm{HST}$ & 8,32 & 8,70 & 8,09 & 8,58 \\
\hline & $45 \mathrm{HST}$ & 9,58 & 9,68 & 9,48 & 9,48 \\
\hline \multicolumn{2}{|l|}{ Umur berbunga ( hari) } & 24,41 & 24,00 & 24,44 & 24,19 \\
\hline \multicolumn{2}{|c|}{ Jumlah buah per tanaman (buah) } & 30,81 & 32,04 & 30,76 & 30,63 \\
\hline \multicolumn{2}{|c|}{ Jumlah buah per tandan (buah) } & 3,66 & 3,53 & 3,57 & 3,56 \\
\hline \multicolumn{2}{|c|}{ Bobot buah pertanaman $(\mathrm{g})$} & 1077,87 & 1255,51 & 1142,50 & 1051,25 \\
\hline \multicolumn{2}{|c|}{ Bobot buah per buah $(\mathrm{g})$} & 34,87 & 36,77 & 34,66 & 37,65 \\
\hline \multicolumn{2}{|l|}{ Potensi hasil (ton/ha) } & 43,11 & 50,22 & 45,70 & 42,05 \\
\hline
\end{tabular}

Pada tabel 1 menunjukkan bahwa konsentrasi pupuk organik cair super ACI berpengaruh tidak nyata pada semua parameter yang diamati. Rahmaddin (2018) yang menyatakan bahwa pengaruh yang tidak nyata dari perlakuan pupuk organik cair disebabkan oleh faktor lingkungan yang tidak mendukung untuk proses penyerapan unsur hara yang terkandung dalam pupuk organik cair. Menurut Dwidjosepotro (2005) menyatakan bahwa suatu tanaman akan tumbuh dengan subur apabila semua unsur hara tersedia dalam jumlah yang cukup dan dalam bentuk yang sesuai untuk dapat diserap oleh tanaman selama masa pertumbuhannya. Sutejo (2002) yang menyatakan bahwa kekurangan salah satu atau beberapa unsur hara dapat menyebabkan pertumbuhan tanaman menjadi terhambat dan apabila unsur hara kurang dari kebutuhan optimal maka pertumbuhan tanaman tidak berjalan dengan baik. Menurut Lingga (2003) menyatakan bahwa dalam pemberian pupuk ada beberapa hal yang perlu diperhatikan yaitu jenis pupuk yang digunakan, kandungan hara, konsentrasi larutan yang diberikan dan waktu pemberian pupuk sebaiknya diberikan pada waktu/saat tanaman memerlukan unsur hara secara intensif agar pertumbuhan dan perkembangannya berlangsung dengan baik.Kelemahan pupuk organik cair adalah sebagai berikut :1) kandungan haranya rendah, 2) lambat tersedia bagi tanaman. Sehingga hanya sedikit yang diserap oleh tanaman (Damanik et al., 2011). 


\section{Pengaruh Varietas terhadap Pertumbuhan dan Hasil Tanaman Tomat}

Hasil analisi ragam menunjukkan bahwa varietas tomat berpengaruh sangat nyata terhadap tinggi tanaman umur 15 dan 30 HST, umur berbunga, jumlah buah pertanaman, bobot buah pertanaman, bobot buah perbuah, potensi hasil dan berpengaruh nyata terhadap tinggi tanaman umur 45 HST, namun tidak berpengaruh nyata terhadap diameter batang umur 15, 30, 45 HST dan jumlah buah pertandan.

Tabel 2 Rata-rata Pertumbuhan dan Hasil Tanaman Tomat Akibat Perlakuan Varietas

\begin{tabular}{|c|c|c|c|c|c|}
\hline \multirow{2}{*}{\multicolumn{2}{|c|}{ Peubah }} & \multicolumn{3}{|c|}{ Perlakuan } & \multirow[b]{2}{*}{$\mathrm{BNJ}_{(0,05)}$} \\
\hline & & $\mathrm{V}_{1}($ Lokal $)$ & $\mathrm{V}_{2}$ (Cherry) & $\mathrm{V}_{3}$ (Karina) & \\
\hline \multirow{3}{*}{$\begin{array}{l}\text { Tinggi Tanaman } \\
(\mathrm{cm})\end{array}$} & $15 \mathrm{HST}$ & $26,23 \mathrm{~b}$ & $18,76 \mathrm{a}$ & $25,36 \mathrm{~b}$ & 3,00 \\
\hline & $30 \mathrm{HST}$ & $70,69 \mathrm{c}$ & $57,18 \mathrm{a}$ & $65,03 \mathrm{~b}$ & 5,30 \\
\hline & $45 \mathrm{HST}$ & $85,42 \mathrm{~b}$ & $80,00 \mathrm{a}$ & $83,08 \mathrm{ab}$ & 4,34 \\
\hline \multirow{3}{*}{$\begin{array}{l}\text { Diameter Batang } \\
(\mathrm{mm})\end{array}$} & $15 \mathrm{HST}$ & 4,19 & 4,13 & 4,45 & - \\
\hline & $30 \mathrm{HST}$ & 8,53 & 8,50 & 8,24 & - \\
\hline & $45 \mathrm{HST}$ & 9,61 & 9,44 & 9,62 & - \\
\hline \multicolumn{2}{|c|}{ Umur Berbunga (hari) } & $25,61 \mathrm{~b}$ & $21,61 \mathrm{a}$ & $25,56 \mathrm{~b}$ & 3,08 \\
\hline \multicolumn{2}{|c|}{$\begin{array}{l}\text { Jumlah Buah Per tanaman } \\
\text { (buah) }\end{array}$} & $33,22 \mathrm{~b}$ & $27,78 \mathrm{a}$ & $31,81 \mathrm{~b}$ & 3,13 \\
\hline \multicolumn{2}{|c|}{ Jumlah Buah Per tandan (buah) } & 3,48 & 3,64 & 3,62 & - \\
\hline \multicolumn{2}{|c|}{ Bobot Buah Per tanaman $(\mathrm{g})$} & $1489,73 b$ & $1004,81 \mathrm{a}$ & $900,81 \mathrm{a}$ & 192,50 \\
\hline \multicolumn{2}{|c|}{ Bobot Buah Per buah $(\mathrm{g})$} & $45,12 \mathrm{c}$ & $21,01 \mathrm{a}$ & $41,83 \mathrm{~b}$ & 3,08 \\
\hline \multicolumn{2}{|c|}{ Potensi Hasil (ton/ha) } & $59,59 \mathrm{~b}$ & $40,19 \mathrm{a}$ & $36,03 \mathrm{a}$ & 7,70 \\
\hline
\end{tabular}

Keterangan : Angka yang diikuti oleh huruf yang sama pada kolomyang sama berbeda tidak nyata pada taraf $5 \%$ (uji BNJ).

Pada tabel 1 menunjukkan bahwa varietas Lokal memberikan pertumbuan lebih baik dibandingkan dengan varietas Cherry dan Karina. Menururt Budianto et al., (2014) menyatakan bahwa setiap varietas memiliki ketahanan yang berbeda, beberapa tanaman dapat melakukan adaptasi dengan cepat, namun sebalikya ada tanaman yang membutuhkan waktu lama untuk dapat beradaptasi dengan lingkungan. Hal ini diakibatkan karena setiap varietas memiliki potensi genetik yang berbeda dalam merespon lingkungan tempat tumbuhnya. Setiap varietas memiliki tinggi tanaman yang berbeda, tinggi tanaman berbagai varietas dikontrol genetik tanaman dan juga lingkungan yang sangat menentukan pertumbuhan tanaman (Kirana dan Sofiari, 2007).

Faktor lingkungan dapat menyebabkan sifat- sifat yang muncul beragam dari suatu tanaman. Suatu varietas yang mempunyai kemampuan memberikan potensi hasil yang tinggi, tetapi jika keadaan lingkungan tidak sesuai maka varietas tidak dapat memberikan potensi hasil yang baik.Kemampuan tanaman tomat agar dapat menghasilkan buah yangbaik tergantung pada sifat genetik dan lingkungan tumbuhnya (Nuraeniet al., 2012). Suhu yang baik untuk pertumbuhan tomat adalah $18^{\circ} \mathrm{C}-25^{\circ} \mathrm{C}$. Suhu harian yang melebihi batas optimum pada tanaman dapat mempercepat pembungaan. Kondisi ini disebabkan karena tanaman akan lebih cepat mengumpulkan satuan panas sehingga berdampak lebih cepatnya tanaman untuk membentuk bunga dan memiliki jumlah bunga yang lebih tinggi (Wiryanta, 2002)

Hasil penelitian dapat dilihat bahwa pertumbuhan dan hasil tanaman tomat lebih rendah dijumpai pada varietas Cherry $\left(\mathrm{V}_{2}\right)$. Hal ini diduga karena Varietas Cherry tidak mampu beradaptasi dengan baik terhadap perubahan iklim atau lingkungan tempat tumbuhnya. Kondisi lingkungan selalu mengalami perubahan tersebut dan karena perubahan tersebut dapat menyebabkan menurunnya produktivitas tanaman tomat (Pujito 2005). 


\section{Kesimpulan}

\section{KESIMPULAN DAN SARAN}

1. Konsentrasi pupuk organik cair super ACI yang cendrung lebih tinggi dijumpai pada konsentrasi pupuk organik cair Super ACI 1,5 ml/ L air.

2. Varietas tomat pertumbuhan dan hasil tanaman tomat terbaik dijumpai pada perlakuan varietas Lokal.

3. Terdapat interaksi yang tidak nyata antara konsentrasi pupuk organik cair Super ACI dan varietas terhadap pertumbuhan dan hasil tanaman tomat.

\section{Saran}

Sebaiknya penanaman tomat dilakukan pada akhir musim hujan agar mendapatkan pertumbuhan dan hasil tanaman tomat yang lebih baik sehingga produksi yang dihasilkan lebih maksimal serta dapat dilakukan penelitian dengan konsetrasi pupuk organik cair super ACI yang sama dengan varietas tomat yang berbeda.

\section{DAFTAR PUSTAKA}

Alamsyah, AR. F., dan N. Fitriyah. 2018. Pengaruh mikoriza dan EM4 terhadappertumbuhan dan produktivitas tanaman tomat (Solanum lycopersicum).Jurnal Ilmiah Hijau Cendekia. 3 (1): 14-19.

Budianto, P.T.H.,R. Wirooedarmo, dan B. Suharto. 2014. Perbedaan laju interaksi pada lahan hutan tanaman industri pinus, jati, dan mahoroni. Jurnal Sumberdaya Alam dan Lingkungan. Hal : 5- 24.

Deamanik, M.M.B., Bachtiar E.H., Fauzi., Sarifuddin dan Hamidah H., 2011. Kesuburan tanah dan pemupukan. USU Press. Medan.

Dwijoseputro, G. 2005. Pengantar Fisiologi Tumbuhan. Gramedia. Jakarta.

Kirana, R., Dan E,Sofari. 2012.Analisi pola segregasi dan distribusi beberapa karakter cabai. Jurnal Hortikultura. 19 (13): 255-263.

Koesriharti., D. S. Mariani dan N. Barunawati. 2017. Respon pertmbuhan dan hasil tanaman tomat (Lycopersicum esculentumMill.) varietas permata terhadap dosis pupuk kotoran ayam dan kcl. Jurnal Produksi Tanaman. 5 (9): 1505-1511.

Lingga, P. 2003. Petunjuk Penggunaan Pupuk. Penebar Swadaya, Jakarta.

Marliah, A., M. Hayati dan I. Muliahsyah. 2012. Pemanfaatan pupuk organik cair terhadap pertumbuhan dan hasil beberapa varietas tomat Licopersicum esculentum L. Jurnal. Agrista. 17(3):122-128.

Nuraeni, A., L, Khairani dan I, Susilawati. 2019. Pengaruh tingkat pemberian pupuk nitrogen terhadap kandungan air dan serat kasar corchorus aestuans. Jurnal Vastura. 9(1):32-35.

Putojo, S. 2005. Benih Tomat. Kanisius. Yokyakarta. 
Rahmaddin, S., R. Irvansyah., dan Y. Husainah. 2008. Pengaruh media tanam dan pemberian pupuk organik cair terhadap pertumbuhan bibit kakao (Theobroma cacao L.). Jurnal. Bionatural. 5(1):1-11.

Salli, M. K., dan L. Leher. 2016. Respon Pertumbuhan beberapa varietas tomat (Lycopersicum esculentum Mill.) yang diapikasikan plant growth promoting rhibacteria (PGPR) di lahan kering. Partner. 22(1) : 431-433.

Suryawati., Wanda dan I. Syofia. 2013.Pengaruh limbah padat (SLUDGE) dan pupuk organik cair terhadap pertumbuhan dan hasil tanaman terung ungu (Solanum melongena). Jurnal Agrum (18) $1: 23-31$.

Sutanto, R. 2002. Pertanian Organik: Menuju Pertanian Alternatif dan Berkelanjutan. Yogyakarta: Kanisius.

Sutejo, M. M., dan A. G.Kartasapoetra. (2002).Pengantar Ilmu Tanah. Rineka Cipta. Jakarta.

Wijayanti, E., D,A, Susila. 2013. Pertumbuhan dan hasil dua varietas tomat (Lycopersicum esculentum Mill.)secara hidroponik dengan beberapa komposisi media tanam. Jurnal Agrohorti 1(1) : $104-112$.

Wijayanti, A., W, Widodo. 2005. Usaha Meningkatkan Kualitas Beberapa Varietas Tomat dengan Sistem Budidaya Hidroponik. J. Ilmu Pertanian. Vol 12 (1) : 77-88.

Wiryanta dan Bernardinus. T. W. 2008. Bertanam Tomat. Jakarta : Agromedia Pustaka. 